Enferm Bras 2020;19(3):193-5

https://doi.org/10.33233/eb.v19i3.4250

\title{
EDITORIAL \\ O biodireito e o Covid-19 no contexto jurídico brasileiro
}

"Os que acham que a MORTE é o maior de todos os males é porque não refletiram sobre os males que a INJUSTIÇA pode causar."

(Sócrates - Filósofo grego)

\begin{abstract}
André Silveira*, Zaida Aurora Sperli Geraldes Soler, D.Sc.**
*Advogado, graduado em Letras pela UNESP, Docente convidado de cursos de pós-graduação lato sensu em medicina do trabalho e enfermagem do trabalho, ${ }^{* *}$ Obstetriz, enfermeira, livredocente em enfermagem obstétrica, docente e orientadora de graduação e pós-graduação lato sensu e stricto sensu, Orientadora de pesquisa que incluirá conteúdo deste editorial
\end{abstract}

Correspondência: André Silveira, Rua Cila, 3260 Redentora 15015-800 São José do Rio Preto $\mathrm{SP}$

André Silveira: andresilveiraadvog@gmail.com

Zaida Aurora Sperli Geraldes Soler: zaidaaurora@gmail.com

O bem mais precioso do homem é a vida, preservada pela saúde e no Brasil esse é um direito para todos os cidadãos brasileiros, amparado pela legislação, no Artigo 196 da Constituição Federal Brasileira de 1988. No ramo das ciências jurídicas, um sistema de saúde ético e justo com a sua prática, frente a uma política pública estruturada, está fundamentado nos princípios e ações da bioética e do biodireito [1]. O Direito vai existir em todas as circunstâncias de mudança na ordem social. Vale lembrar do brocardo jurídico: ubi societas, ibi ius, ou seja, onde está a sociedade, está o direito.

O Programa Regional de Bioética, que é vinculado à Organização Pan-Americana de Saúde (OPAS), definiu que a bioética trabalha a serviço da vida, tendo um amplo campo de atuação, que inclui a vida, a saúde e o ambiente. A bioética objetiva aproximar a ciência das novas questões humanitárias, enquanto o biodireito faz a tutela jurídica por meio de normas legais destinadas a proteger a vida e a saúde humana, aproximando-se o mais possível às demandas sociais [2].

Então, a Bioética e o Biodireito andam necessariamente juntos com os direitos humanos, sendo necessária a intervenção do direito para regular as questões bioéticas de forma legítima e suficiente. $O$ biodireito fica configurado como um conjunto de leis positivas que visam estabelecer a obrigatoriedade de observância dos mandamentos éticos, com base em legislação adequada na regulação de atividades e relações desenvolvidas pelas biociências e biotecnologias. O fim é manter a integridade e a dignidade humana frente às conquistas científicas em favor da vida [3].

No ramo das ciências jurídicas, o biodireito tem por objetivo cuidar de normas reguladoras a respeito do comportamento do ser humano diante dos avanços das ciências biológicas e das ciências da saúde. Nesse contexto, a bioética vem exercer seu papel fundamental de aproximação das ciências humanas às ciências biológicas, e o biodireito, por meio do princípio da cooperação, vem exercer a contribuição jurídica para o progresso e para a proteção da vida [4].

Enquanto a ética tem intenções universais, preocupa-se com a interiorização de condutas boas e requer voluntariedade (livre adesão), o direito ocupa-se dos efeitos sociais da exteriorização de determinadas condutas, impõe-se com o obrigatório (coercibilidade) e representa apenas a sociedade em que está inserido [5]. 
O mundo tomou ciência, tardiamente, que desde novembro de 2019, na China, surgiu uma nova infecção por coronavírus, com características epidemiológicas clínicas de disseminação rápida e a capacidade de infectar uma população em geral suscetível [6].

Tem causado muita inquietação, desvelando as fragilidades dos sistemas de saúde em diferentes partes do mundo, a pandemia de coronavírus (COVID-2019), pela amplificação das consequências para a saúde pública e aspectos bioéticos relacionados. As autoridades de saúde pública buscam conter o vírus e mitigar os efeitos deletérios sobre a saúde da população mundial [7].

Ainda são muitas as dúvidas, experiências e contradições no controle da pandemia de Covid-19 sob a perspectiva da epidemiologia e das políticas públicas brasileiras. Frente à impossibilidade de redução de pessoas susceptíveis por meio de estratégias vacinais, a redução da velocidade da curva epidêmica precisa ocorrer por meio de políticas públicas que visem a proteção ao trabalhador, ampliação do investimento no setor saúde e ações de isolamento físico social [8].

Então, diante da exacerbada mudança social que se vincula à pandemia do Covid-19, o sistema jurídico brasileiro se encarregou de disciplinar normas reguladoras e regulamentadoras para tratar dessa questão. Foi deflagrado pelo Congresso Nacional o estado de calamidade pública como medida para as ações de combate à pandemia do Covid-19, por meio da Lei no 13.979, de 6 de fevereiro de 2020, que, posteriormente, foi regulamentada pela Portaria $n \circ 0356$, de 11 de março de 2020, do Ministro do Estado da Saúde [9].

Em razão do avanço da pandemia do Covid-19, a questão que tem que ser resolvida é a demanda por leitos como forma de se efetivar o exercício do direito à saúde. E o desafio que o mundo enfrenta é a cura para o coronavírus.

$\mathrm{Na}$ contramão dessa questão, países como Itália, Inglaterra, Espanha e Estados Unidos chegaram a adotar o parâmetro da escolha, no qual o sistema de saúde teve que escolher em prestar assistência nos hospitais a quem tinha chance real de recuperação e deixar de prestar atendimento a quem já estava com o estado de saúde muito agravado e comprometido. Ainda, é possível citar o caso da Itália, onde o que se viu foi a limitação de leitos. Dilemas ligados à bioética vieram à tona, notadamente quanto à autonomia do paciente de não ressuscitação e/ou à ordem de ressuscitação [9-12].

Convém ressaltar que a pandemia do Covid-19 está impactando o sistema jurídico. É certo que o Direito Civil já contava com alguns institutos jurídicos para resolver situações de crise, como é o caso do instituto do caso fortuito e força maior, da exceção de contrato não cumprido (teoria da imprevisão) e o da resolução por onerosidade excessiva. Mas temas ligados ao direito da personalidade começaram a entrar em conflito (autonomia $x$ solidariedade/vulnerabilidade), e o que se vê nos dias atuais é a restrição dos direitos fundamentais consagrados no artigo $5^{\circ} \mathrm{e}$ do direito à saúde previsto no artigo 196, ambos da Constituição Federal de 1988 [9-12].

Questões ligadas à judicialização da saúde tornam evidente, ou seja, se as ações judiciais para o fornecimento de medicamento e para a efetivação do tratamento do Covid-19 se torna eficaz ou ineficaz, diante de outras questões relacionadas a escassez de recursos e a terminalidade da vida [10].

Considerando toda essa polêmica e fundamentada nos princípios e ações da bioética, a Lei $n^{\circ}$ 13.979/2020 vem dispor sobre a restrição de alguns direitos do cidadão, que são as medidas para enfrentamento da emergência de saúde pública de importância internacional decorrente do coronavírus (artigo, $3^{\circ}$, incisos I a VIII), que objetivam a proteção da coletividade (artigo $1^{\circ}, \S 1^{\circ}$ ), além de fazer considerações sobre o isolamento e a quarentena (artigo $2^{\circ}$, incisos I e II, respectivamente) e reconhecer os direitos que deverão ser assegurados às pessoas afetadas pelas medidas previstas na lei (artigo $3^{\circ}$, $§ 2^{\circ}$, incisos I, II e III) [10-12].

De acordo com a Lei oㅜ13.979/2020, cada autoridade local é responsável pela tomada de decisões (art. $3^{\circ}, \S 7^{\circ}$ ), ao mesmo tempo em que se tem que ter ciência do problema de pacientes assintomáticos, pois são estes que vão causar o colapso do sistema de saúde. É indiscutível que atualmente os pacientes estão vulneráveis ao sistema de saúde, uma vez que a maior parte dos hospitais possui dificuldades de encontrar equipamentos de proteção individual aos profissionais da saúde [12].

Em síntese, a Lei no 13.979/2020 acaba por restringir o direito à liberdade individual, a fim de que seja assegurado e garantido o direito à saúde, põe em prática a restrição aos direitos fundamentais e a restrição à atuação do Estado. Essa é a tarefa do biodireito: concretizar a retomada dos direitos fundamentais do indivíduo e de toda coletividade, assim como aprender a manejar os instrumentos de saúde pública [10-12]. 
Por fim, diante de todo o cenário jurídico atual no Brasil, não foram estabelecidos pela Lei no 13.979/2020, os limites de atuação dos direitos fundamentais. A Lei oㅜ 13.979/2020 não previu instrumentos de freios e não previu como vai ser a retomada da vida habitual que havia antes da pandemia do Covid-19. Será retomada a vida que havia antes?

"A justiça não consiste em ser neutro entre 0 certo e o errado, mas em descobrir o certo e sustentá-lo, onde quer que ele se encontre, contra o errado". Theodore Roosevelt

1. Ribas JLC, Rodrigues ICG, Garcia IF, Dantos VLP. Bioética: análise da compreensão de biodireito por meio de cases. Rev Latinoam Bioet 2018;18(2):185-94. https://doi.org/10.18359/rlbi.3294

2. Pereira HMK. Biodireito como lugar de desenvolvimento de perspectivas jurídicas para a proteção da vida. Revista de Direito Sanitário 2016;16(3):75-81. https://doi.org/10.11606/issn.2316-9044.v16i3p75-81

3. Farinon MJ. Ética, Justiça e Educação sob o enfoque da Alteridade. Cadernos de Pesquisa 2018;48(167):204-24. https://doi.org/10.1590/198053144687

4. Brito ES, Ventura CAA. Bioética e Biodireito: Reflexões à luz do princípio fundamental da dignidade da pessoa humana. Brazilian Journal of Forensic Sciences, Medical Law and Bioethics 2013;2(2):10:141-53. https://doi.org/10.17063/bjfs2(2)y2013141

5. Rivabem FS. Biodireito: uma disciplina autônoma? Rev Bioét 2017;25(2):282-9.

6. Laishuan W, WangYuan S, Tiantian X, Jianhua F, Xing F, Dezhi M et al. Chinese expert consensus on the perinatal and neonatal management for the prevention and control of the 2019 novel coronavirus infection (First edition). Working Committee on Perinatal and Neonatal Management for the Prevention and Control of the 2019 Novel Coronavirus Infection. Annals of Translation Medicine 2020;8(3). https://doi.org/10.21037/apm.2020.02.02

7. Garfin DR, Silver RC, Holman EA. The novel coronavirus (COVID-2019) outbreak: Amplification of public health consequences by media exposure. Health Psychol 2020;39(5):355-7. https://doi.org/10.1037/hea0000875

8. Rafaell RMR, Neto M, Carvalho MMB, David HMSL, Acioli S, Faria MGA, Epidemiologia, políticas públicas e pandemia de Covid-19: o que esperar no Brasil? Rev Enferm UERJ 2020;28:49570.

9. Brasil. Lei n. 10.406, de 10 de janeiro de 2002. Lei de introdução às normas do Direito brasileiro. Institui o Código Civil. Diário Oficial da União. 11 jan 2002.

10. Brasil. Lei n. 13.979, de 06 de fevereiro de 2020. De saúde pública de importância internacional decorrente do coronavírus responsável pelo surto de 2019. Diário Oficial da União. 07 fev 2020.

11. Brasil. Portaria n. 356, de 11 de março de 2020. Dispõe sobre a regulamentação 13.979, de 06 de fevereiro de 2020, que estabelece as medidas para enfrentamento da emergência de saúde pública de importância internacional decorrente do coronavírus (COVID-19). Diário Oficial da União. 12 mar 2020.

12. Brasil. Vade Mecum COVID -19 - Leis e Portarias. Compilação da legislação aplicável à instrumentalização jurídica das ações de combate à pandemia do Covid-19. Diário Oficial da União - DOU. 27 ab 2020 